\begin{tabular}{|c|c|}
\hline Title & $\begin{array}{l}\text { In Situ Optical and Electrochemical AFM Monitoring of Cu Electrodeposition Process on Bare and (NH4)2S-T reated p- } \\
\text { GaA s(001) Surfaces }\end{array}$ \\
\hline Author(s) & T amura, Kazuhisa; Kondo, Toshihiro; U osaki, Kohei \\
\hline Citation & $\begin{array}{l}\text { Journal of The Electrochemical Society, 147(9), 3356-3360 } \\
\text { https://doi.org/10.1149/1.1393906 }\end{array}$ \\
\hline Issue Date & 2000 \\
\hline Doc URL & http:/hdl.handle.net/2115/50236 \\
\hline Rights & $\begin{array}{l}\text { (1) The Electrochemical Society, Inc. 2000. A II rights reserved. Except as provided under U.S. copyright law, this work } \\
\text { may not be reproduced, resold, distributed, or modified without the express permission of The Electrochemical Society } \\
\text { (ECS). The archival version of this work was published in J. Electrochem. Soc. } 2000 \text { volume 147, issue 9, 3356-3360. }\end{array}$ \\
\hline Type & article \\
\hline File Information & JES147-9_3356-3360.pdf \\
\hline
\end{tabular}

Instructions for use 


\section{In Situ Optical and Electrochemical AFM Monitoring of $\mathrm{Cu}$ Electrodeposition Process on Bare and ?(??NH? 4 ?)? 2 ?S??- ?Treated p-GaAs(001) Surfaces}

Kazuhisa Tamura, Toshihiro Kondo and Kohei Uosaki

J. Electrochem. Soc. 2000, Volume 147, Issue 9, Pages 3356-3360. doi: $10.1149 / 1.1393906$
Email alerting Receive free email alerts when new articles cite this article - sign up in the service box at the top right corner of the article or click here




\title{
In Situ Optical and Electrochemical AFM Monitoring of Cu Electrodeposition Process on Bare and $\left(\mathrm{NH}_{4}\right)_{2} \mathrm{~S}$-Treated p-GaAs(001) Surfaces
}

\author{
Kazuhisa Tamura, Toshihiro Kondo, and Kohei Uosaki*,z \\ Physical Chemistry Laboratory, Division of Chemistry, Graduate School of Science, Hokkaido University, Sapporo 060-0810, Japan
}

\begin{abstract}
The initial process of $\mathrm{Cu}$ electrodeposition on bare and $\left(\mathrm{NH}_{4}\right)_{2} \mathrm{~S}$-treated $\mathrm{p}-\mathrm{GaAs}(001)$ surfaces was investigated using electrochemical, reflectance, light-scattering, and in situ electrochemical atomic force microscopy (AFM) measurements. The reflectance and light-scattering measurements showed that on both the bare and $\left(\mathrm{NH}_{4}\right)_{2} \mathrm{~S}$-treated surfaces, Cu deposition occurred in a cluster growth mode and the $\mathrm{Cu}$ clusters grew in the $z$-direction at a relatively negative potential where the limiting current was observed. The potential dependencies of the reflectance and scattered light intensity obtained at various potential scan rates showed that the size of the $\mathrm{Cu}$ clusters was smaller at the higher scan rate. The charge due to the $\mathrm{Cu}$ deposition at the $\left(\mathrm{NH}_{4}\right)_{2} \mathrm{~S}$-treated electrode was nearly half that of the bare surface under the same experimental conditions, and AFM images showed a smaller number of $\mathrm{Cu}$ clusters at the $\left(\mathrm{NH}_{4}\right)_{2} \mathrm{~S}$-treated surfaces, suggesting a reduction in the defect sites by the $\left(\mathrm{NH}_{4}\right)_{2} \mathrm{~S}$ treatment.

(c) 2000 The Electrochemical Society. S0013-4651(00)01-121-6. All rights reserved.
\end{abstract}

Manuscript submitted January 28, 2000; revised manuscript received May 22, 2000.

The metal/semiconductor interface is one of the basic key components in electronic devices and has been the subject of significant scientific interest. GaAs is recognized as one of the most important semiconductor materials because of its high electron mobility, which is essential for processing high-frequency signals. Thus, metal deposition on GaAs has been investigated in various aspects by using many techniques and the electrochemical deposition of $\mathrm{Cu}$ on $\mathrm{GaAs}$ has been studied by many research groups. Vereecken et al. reported that on $\mathrm{n}$ - and $\mathrm{p}-\mathrm{GaAs}(001)$ electrodes, $\mathrm{Cu}^{2+}$ was reduced to $\mathrm{Cu}^{+}$ before the reduction to $\mathrm{Cu}^{0}$ in a solution containing the chloride anion, but no $\mathrm{Cu}^{+}$intermediate was detected on $\mathrm{n}$ - and $\mathrm{p}-\mathrm{GaAs}(001)$ electrodes in a solution containing sulfate ion. ${ }^{1,2}$ Scherb and Kolb followed the electrochemical deposition process of $\mathrm{Cu}$ in the presence of a side reaction by photoreflectivity measurements. ${ }^{3}$ We have found that the randomly distributed $\mathrm{Cu}$ clusters were formed on a $\mathrm{p}-\mathrm{GaAs}(001)$ surface in a solution containing chloride or sulfate ion by using in situ electrochemical atomic force microscopy (AFM). ${ }^{4-6}$ Smilgies et al. showed that the $\langle 100\rangle$ direction of the deposited $\mathrm{Cu}$ was aligned with the $\langle 110\rangle$ direction of the $n-G a A s(001)$ surface by using X-ray diffraction. ${ }^{7}$ We also found that $\mathrm{Cu}$ nanoclusters with a shorter $\mathrm{Cu}-\mathrm{Cu}$ distance than that of the bulk $\mathrm{Cu}$ were formed during an early stage of $\mathrm{Cu}$ electrochemical deposition on a p-GaAs(001) electrode by using in situ surface extended X-ray absorption fine structure (EXAFS). ${ }^{8,9}$ Scherb et al. examined the structure of the $\mathrm{Cu}$ deposition in $\mathrm{n}$ - and $\mathrm{p}-\mathrm{GaAs}(001)$ by $\mathrm{X}$-ray standing waves. ${ }^{10}$ Although these results provided detailed information about the microscopic structures of the deposits, i.e., atomic level structure, they did not give the information about the deposition process in a macroscopic sense, i.e., thickness of deposit and morphology of the electrode surface, which are also important for understanding the deposition process. It was demonstrated that reflectance and lightscattering measurements are convenient real-time methods for evaluating the thickness of thin films formed on electrodes and the surface roughness of the electrodes, respectively. ${ }^{3,11}$ Thus, the simultaneous measurement of the reflectance and light scattering should provide detailed macroscopic information about the surface structure of the electrode during the deposition process.

It is well known that GaAs has many surface states, which is the major reason for the Fermi level pinning and poor thermionic emission characteristics. ${ }^{12}$ To reduce the density of the surface states, surface treatments have been extensively investigated. ${ }^{13-18}$ Sik et al. reported that the surface treatment with $\left(\mathrm{NH}_{4}\right)_{2} \mathrm{~S}$ solution gave oxide-free surfaces with few surface states. ${ }^{19}$ Sandrof et al. found

\footnotetext{
* Electrochemical Society Active Member.

z E-mail: uosaki@pcl.sci.hokudai.ac.jp
}

the formation of $\mathrm{As}_{r} \mathrm{~S}_{y}$ chemical bonds using X-ray photoelectron spectroscopy (XPS). ${ }^{20}$ Maeyama et al. determined the surface structure of the $\left(\mathrm{NH}_{4}\right)_{2} \mathrm{~S}$-treated surface by EXAFS. ${ }^{21}$ It was shown that the $\left(\mathrm{NH}_{4}\right)_{2} \mathrm{~S}$ treatment improved the capacitance-voltage characteristics of a GaAs-based metal-insulator-semiconductor device. ${ }^{22}$

In this paper, the initial process of $\mathrm{Cu}$ electrodeposition on bare and $\left(\mathrm{NH}_{4}\right)_{2} \mathrm{~S}$-treated surfaces was investigated by simultaneous reflectance and light-scattering measurements. These results indicate that on both the bare and $\left(\mathrm{NH}_{4}\right)_{2} \mathrm{~S}$-treated surfaces, $\mathrm{Cu}$ deposition initially occurred in the Volmer-Weber growth mode and the $\mathrm{Cu}$ clusters then grew in the $z$-direction at a relatively negative potential where the limiting current was observed. These measurements also showed that the $\left(\mathrm{NH}_{4}\right)_{2} \mathrm{~S}$ treatment lead to a reduction in the surface defects, which was confirmed by in situ AFM.

\section{Experimental}

Reagent-grade $\mathrm{H}_{2} \mathrm{SO}_{4}, \mathrm{CuSO}_{4}$, and ethanol were obtained from Wako Pure Chemicals and used without further purification. Water was purified using a Milli-Q water purification system (Yamato, WQ-500).

Single crystalline Zn-doped p-GaAs(001) wafers (Mitsubishi Chemical Corp., doping density $1.0 \times 10^{19} \mathrm{~cm}^{-3}$ ) were used as the electrodes. The wafers were cleaned in hot ethanol, dipped in $3 \mathrm{M}$ $\mathrm{HCl}$ to remove the surface oxide, and then rinsed with pure water. The $\left(\mathrm{NH}_{4}\right)_{2} \mathrm{~S}$ treatment was carried out by immersing the sample for $30 \mathrm{~min}$ in the $\left(\mathrm{NH}_{4}\right)_{2} \mathrm{~S}$ solution at $90^{\circ} \mathrm{C} .{ }^{19} \mathrm{Ohmic}$ contact was secured using an InZn alloy. The GaAs sample was fixed on a sample holder, which was made from polytetrafluoroethylene (PTFE), and then placed in a photoelectrochemical cell, which was made from Pyrex with an optically flat window. The electrode potential was controlled by a potentiostat (Hokuto Denko, HA151) and a function generator (Hokuto Denko, HB-111) with respect to the $\mathrm{Ag} / \mathrm{AgCl}$ electrode (1 M $\mathrm{KCl})$. The counter electrode was a Pt wire.

Reflectance and light-scattering measurements were carried out by using a $10 \mathrm{~mW}$ He-Ne laser as the light source and Si photodiodes as detectors. Si photodiodes were placed in the reflected light path and next to the optical window for the reflectance and lightscattering measurements. The incident angle of the laser beam was ca. $80^{\circ}$ and the polarization was perpendicular to the surface. The output of the Si photodiodes was captured by a computer through a 12 bit analog/digital (A/D) converter. The normalized reflectance change $(\Delta R / R)$ is defined as

$$
\frac{\Delta R}{R}=\frac{R(E)-R_{0}}{R_{0}}
$$


where $R(E)$ and $R_{0}$ are the reflectivities at a given potential, $E$, and at the potential where no deposition takes place, respectively. ${ }^{23}$

In situ electrochemical AFM measurements were carried out using a Nanoscope II or E controller with an electrochemical AFM unit (Digital Instruments) in a constant force mode. The spring constant of the cantilevers was $0.58 \mathrm{nN} / \mathrm{m}$. A glass fluid cell supplied by Digital Instruments was used. A Pt wire and $\mathrm{Ag} / \mathrm{AgCl}$ electrode were used as the counter and reference electrodes, respectively. Details of the AFM measurements were previously described. ${ }^{4}$

\section{Results and Discussion}

Deposition on a bare GaAs surface.-Figures 1-4 show the simultaneously obtained potential dependencies of current, $\Delta R / R$, and scattered light intensity change at the p-GaAs(001) electrode measured in $0.1 \mathrm{M} \mathrm{H}_{2} \mathrm{SO}_{4}$ solution containing $1 \mathrm{mM} \mathrm{CuSO}_{4}$ when the potential was scanned between +0.1 and $-0.49 \mathrm{~V}$ at various sweep rates. The scattered light intensity was reported with respect to that at $+0.1 \mathrm{~V}$.

When the potential was scanned from $+0.1 \mathrm{~V}$ in the negative direction at a scan rate of $2 \mathrm{mV} \mathrm{s}^{-1}$ (Fig. 1), the cathodic current started to flow at $c a$. $0 \mathrm{~V}$, reached a maximum at $-0.14 \mathrm{~V}$, and decreased to a relatively constant value. The $\Delta R / R$ increased very slightly and the scattered light intensity did not change at the beginning, but when the current approached a peak at $-0.14 \mathrm{~V}$, the $\Delta R / R$ and the scattered light intensity started to decrease and increase sharply, respectively. At $c a$. $-0.24 \mathrm{~V}$ where current reached a constant value, the $\Delta R / R$ value started to increase and the increment of

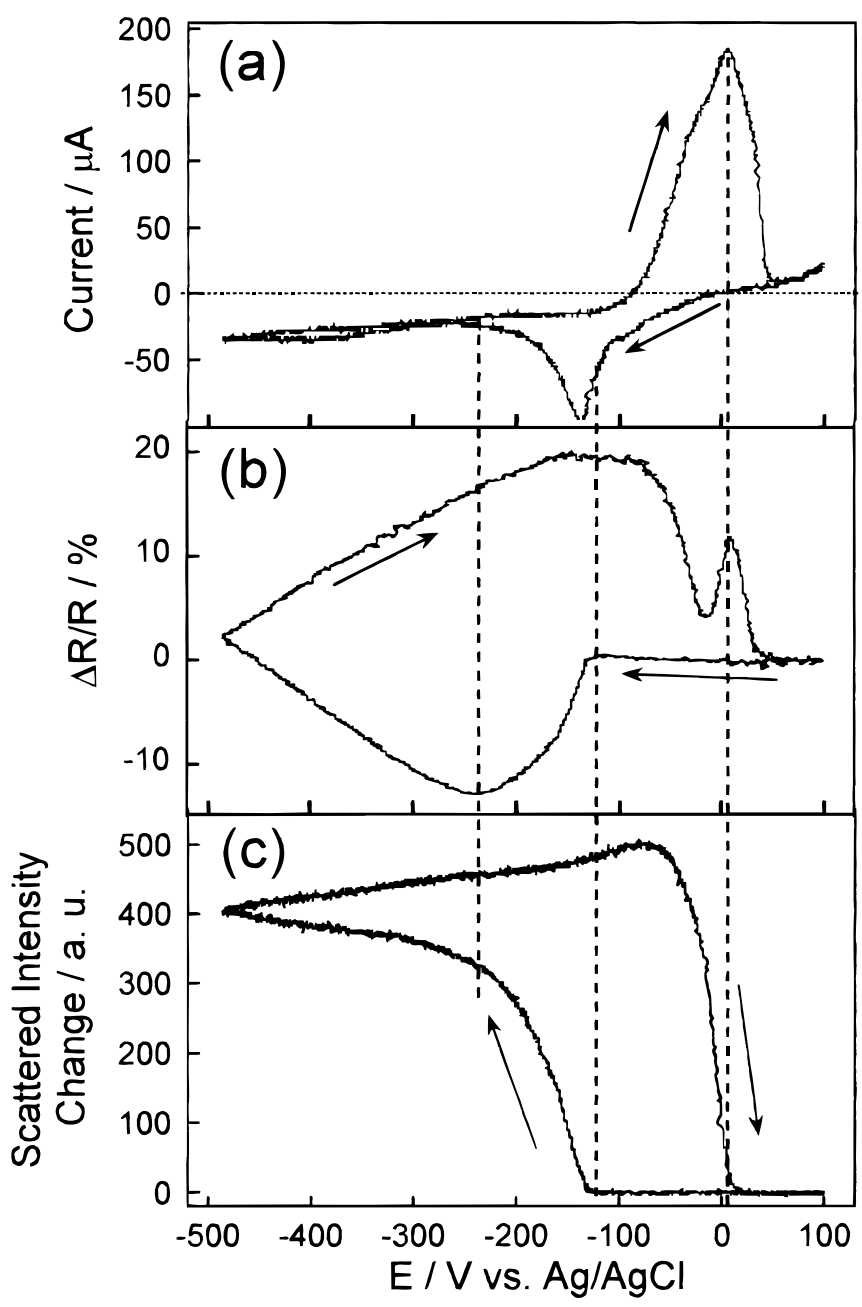

Figure 1. (a) Cyclic voltammogram, (b) $\Delta R / R$, and (c) scattered light intensity of p-GaAs(001) electrode in $0.1 \mathrm{M} \mathrm{H}_{2} \mathrm{SO}_{4}$ solution containing $1 \mathrm{mM}$ $\mathrm{CuSO}_{4}$. Sweep rate $2 \mathrm{mV} \mathrm{s}^{-1}$.

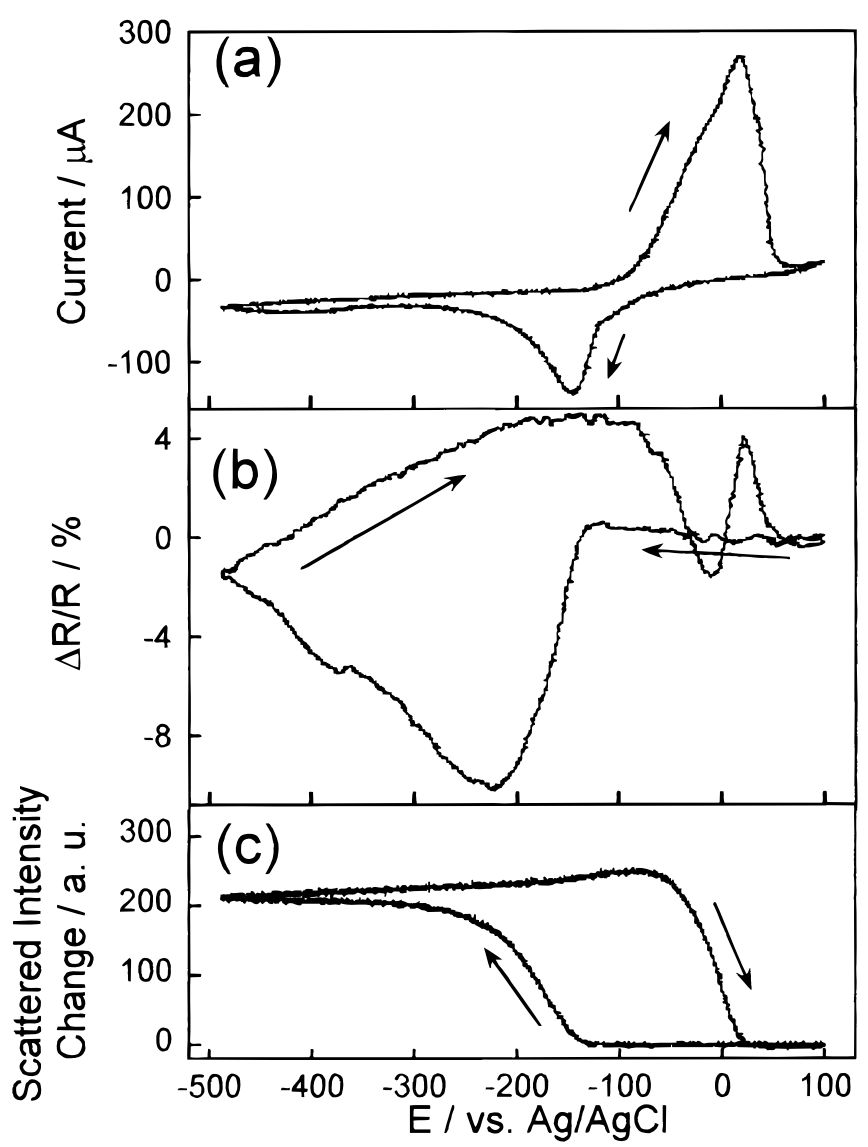

Figure 2. (a) Cyclic voltammogram, (b) $\Delta R / R$, and (c) scattered light intensity of p-GaAs(001) electrode in $0.1 \mathrm{M} \mathrm{H}_{2} \mathrm{SO}_{4}$ solution containing $1 \mathrm{mM}$ $\mathrm{CuSO}_{4}$. Sweep rate $5 \mathrm{mV} \mathrm{s}^{-1}$.

the scattered light intensity became less significant. Even after the potential scan was reversed to the positive direction at $-0.49 \mathrm{~V}$, a cathodic current still flowed and both the $\Delta R / R$ and the scattered light intensity increased at a constant rate. At $c a$. $-0.12 \mathrm{~V}$ where the cathodic current still flowed, the $\Delta R / R$ value became constant and the scattered light intensity started to increase. The current became anodic at $c a .-0.09 \mathrm{~V}$. As the potential became more positive, the $\Delta R / R$ value and the scattered light intensity started to rapidly decrease. The $\Delta R / R$ showed a minimum, increased again, and reached a maximum when current reached the maximum. The scattered light intensity decreased to its original value at the potential where the current reached a maximum. After the current reached a maximum, the $\Delta R / R$ value decreased to its original value and the scattered light intensity stayed at its original value as the potential was scanned more positively.

Although similar potential dependencies of current, the $\Delta R / R$ value, and the scattered light intensity were observed at all the scan rates (Fig. 2-4), several scan rate-dependent features were noticed. Potentials for the cathodic and anodic current peaks shifted toward the negative and positive directions, respectively, and the minimum of the $\Delta R / R$ value in the negative potential scan and the maximum of the scattered light intensity became smaller as the scan rate increased. When the scan rate was $2,5,10$, and $20 \mathrm{mV} \mathrm{s}{ }^{1}$, the minimum of the $\Delta R / R$ value was $-13,-10,-4$, and $0 \%$, and the maximum of the scattered light intensity was 500, 250, 60, and 10, respectively. Furthermore, the minimum and the maximum of the $\Delta R / R$ value observed in the positive potential scan became less significant as the scan rate increased.

To analyze these results in more detail, the $\Delta R / R$ value and the scattered light intensities obtained at the various sweep rates were plotted as a function of the charge passed during the deposition in Fig. 5. The charge dependencies of the $\Delta R / R$ value and the scattered 


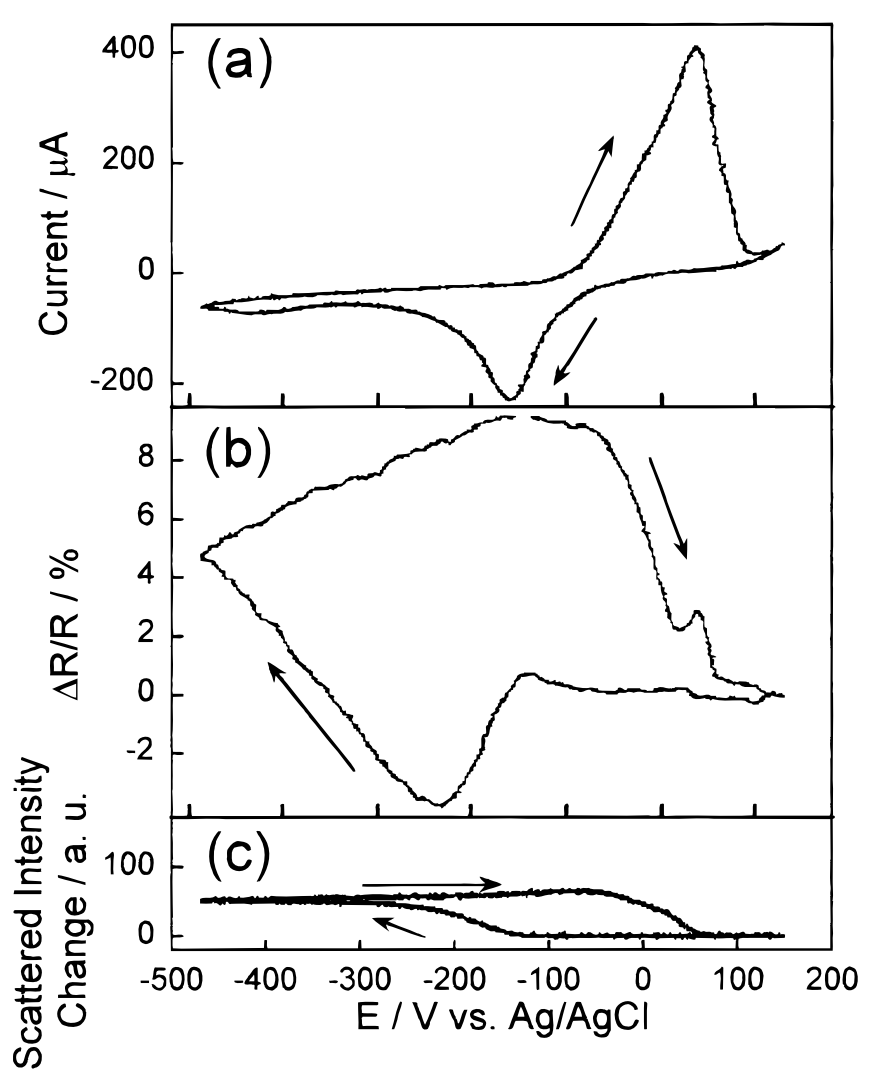

Figure 3. (a) Cyclic voltammogram, (b) $\Delta R / R$, and (c) scattered light intensity of p-GaAs(001) electrode in $0.1 \mathrm{M} \mathrm{H}_{2} \mathrm{SO}_{4}$ solution containing $1 \mathrm{mM}$ $\mathrm{CuSO}_{4}$. Sweep rate $10 \mathrm{mV} \mathrm{s}^{-1}$.

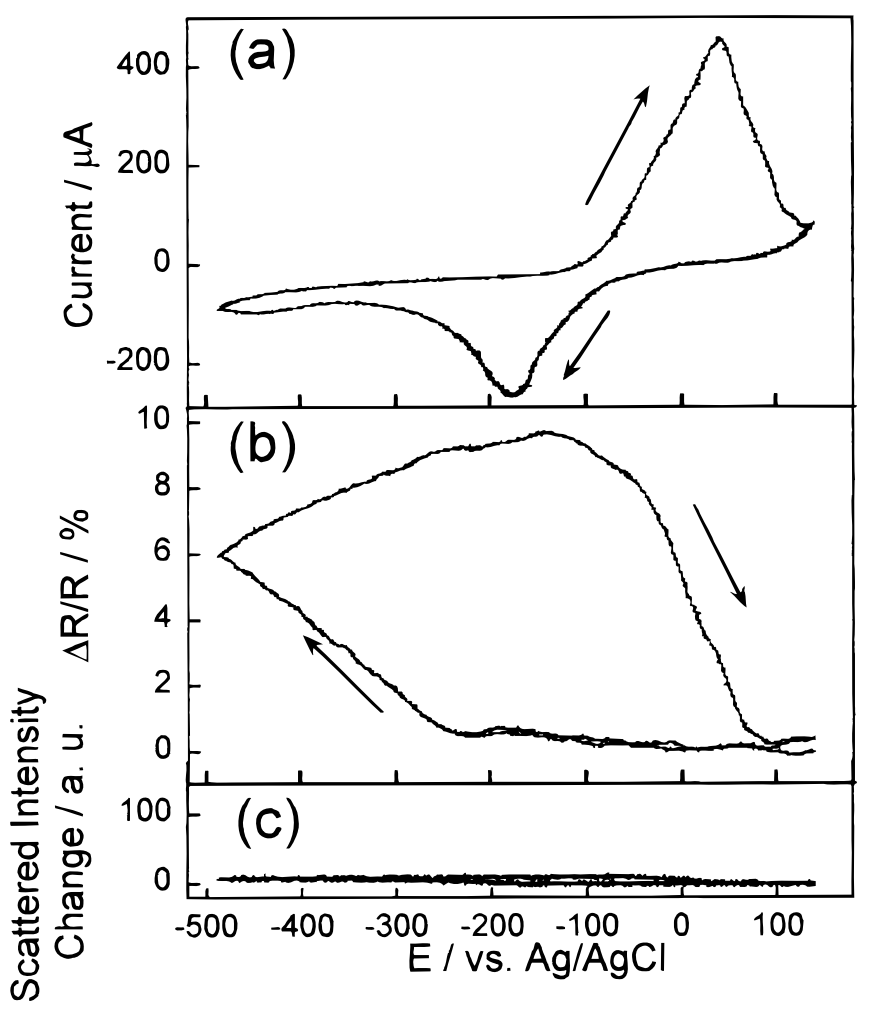

Figure 4. (a) Cyclic voltammogram, (b) $\Delta R / R$, and (c) scattered light intensity of p-GaAs(001) electrode in $0.1 \mathrm{M} \mathrm{H}_{2} \mathrm{SO}_{4}$ solution containing $1 \mathrm{mM}$ $\mathrm{CuSO}_{4}$. Sweep rate $20 \mathrm{mV} \mathrm{s}^{-1}$. light intensity clearly showed that the deposition process can be divided into three regions. In the first region, the $\Delta R / R$ value increased very slightly and the scattered intensity did not change despite the current flow. There is no obvious relation between the sweep rate and the charge passed in the first region. In the second region, the $\Delta R / R$ value decreased in proportion to the charge with almost the same rate at all scan rates except in the case of $20 \mathrm{mV} \mathrm{s}^{-1}$. The scattered light intensity increased in proportion to the charge in this region. The slope depended on the scan rate in this case with the smaller values at the higher scan rates. In the third region, the $\Delta R / R$ value linearly increased with the charge with a constant rate at all scan rates. The scattered light intensity also increased linearly with the charge but at a much smaller rate than in the second region.

For the three-phase system such as the present case, i.e., (i) the bulk electrolyte, (ii) the thin film, and (iii) the bulk electrode, when the thickness of the thin film, $d$, is much smaller than the wavelength of the incident light, $\lambda, \Delta R / R$ is given by ${ }^{23}$

$$
\frac{\Delta R}{R}=\frac{8 \pi d \sqrt{\epsilon_{1}} \cos \varphi}{\lambda} \operatorname{Im}\left(\frac{\hat{\epsilon}_{2}-\hat{\epsilon}_{3}}{\epsilon_{1}-\hat{\epsilon}_{3}}\right)
$$

where $\varphi$ is the incident angle, $\epsilon_{1}$ is the dielectric constants of the electrolyte, and $\bar{\epsilon}_{2}$ and $\widehat{\epsilon}_{3}$ are the complex dielectric constants of the film and the substrate, respectively. $\bar{\epsilon}$ is given by

$$
\widehat{\epsilon}=\epsilon^{\prime}-i \epsilon^{\prime \prime}
$$

where $\epsilon^{\prime}$ and $\epsilon^{\prime \prime}$ describe the dispersion and absorption in a medium, respectively. Equation 2 shows that the $\Delta R / R$ value is proportional to the thickness of the thin film as long as the complex dielectric constants of the thin film are independent of the thickness.

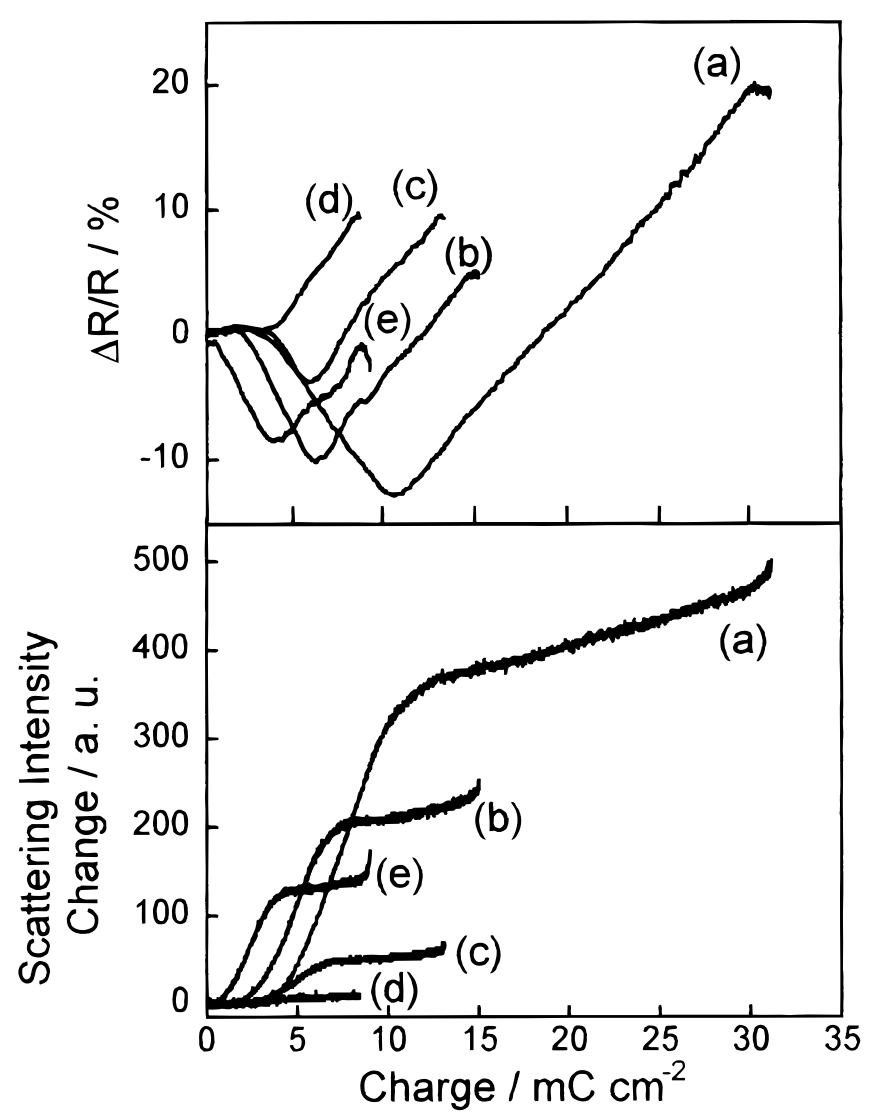

Figure 5. Coverage dependence of $\Delta R / R$ (top) and scattered light intensity (bottom) of (a-d) p-GaAs(001) and (e) $\left(\mathrm{NH}_{4}\right)_{2} \mathrm{~S}$-treated GaAs electrode in $0.1 \mathrm{M} \mathrm{H}_{2} \mathrm{SO}_{4}$ solution containing $1 \mathrm{mM} \mathrm{CuSO}_{4}$. Sweep rate are (a) 2, (b) 5 , (c) 10 , (d) 20 , and (e) $5 \mathrm{mV} \mathrm{s}^{-1}$. 
According to the Rayleigh scattering theory, when the size of the cluster is much smaller than $\lambda$, the scattered light intensity, $I$, is given by

$$
I=\frac{\pi^{2}}{2}(1+\cos \theta) \frac{c N V^{2}}{\epsilon_{0}^{2} r^{2} \lambda^{4}} I_{0}
$$

where $\theta$ is the scattering angle, $N$ is the number of the scatterers, $V$ is the volume of the scatterers, $\epsilon_{0}$ is the permittivity of the free space, $r$ is the distance between the scatterers and the detector, and $c$ is a constant. This relation shows that the scattered light intensity is proportional to the square of the volume of the cluster and the number of clusters. ${ }^{11,24}$

Vereecken et al. have reported that the reduction of $\mathrm{Cu}^{2+}$ to $\mathrm{Cu}^{0}$ proceeds by a one-step reaction in a solution containing sulfate anion. ${ }^{1}$ Thus, the cathodic current observed in this study should be mainly due to the electrodeposition of $\mathrm{Cu}$, and a simulation of the $\Delta R / R$ for the electrolyte/Cu/GaAs three-phase system based on Eq. 2 showed that the $\Delta R / R$ value increases with the thickness of $\mathrm{Cu}^{23} \mathrm{In}$ the first region, however, the $\Delta R / R$ value increased very slightly and the scattered light intensity did not change even though a cathodic current flowed. One possible reason for this observation is an electrochemical cathodic reaction other than the $\mathrm{Cu}$ deposition, e.g., the electrochemical reduction of surface oxides on $\mathrm{GaAs}$ such as $\mathrm{As}_{2} \mathrm{O}_{3}$, $\mathrm{As}_{2} \mathrm{O}_{5}$, and/or $\mathrm{Ga}_{2} \mathrm{O}_{3}{ }^{19}$ took place. A simulation of the $\Delta R / R$ value for electrolyte/GaAs oxide/GaAs three-phase system based on Eq. 2 with the complex dielectric constants of the surface oxide ${ }^{25}$ showed that the $\Delta R / R$ value increases if the surface oxide is removed. In the present result, the $\Delta R / R$ value increased very slightly at the beginning, and the thickness of the oxide layer estimated by the charge passed as well as the increase in the $\Delta R / R$ value in the first region was $c a .1 \mathrm{~nm}$, which is in agreement with the value of $1-3 \mathrm{~nm}$ as the thickness of the native surface oxide previously reported. ${ }^{19,26}$ The variation in the charge passed in the first region should be due to the difference in the thickness of the surface oxide, which depended on the experimental procedure. Thus, we can conclude that the electrochemical reduction of GaAs oxide occurred in the first region.

After the electrochemical reduction of the surface oxide was completed, the electrodeposition of $\mathrm{Cu}$ started and the cathodic current sharply increased (second region). In this region, the scattered light intensity increased, and the $\Delta R / R$ value decreased as the electrodeposition of $\mathrm{Cu}$ proceeded. The decrease in the $\Delta R / R$ value should be caused by the increase in the scattered light, which reflects the increase in the surface roughness. Thus, $\mathrm{Cu}$ clusters grew mainly in size not in number with the increase in the amount of electrodeposited $\mathrm{Cu}$. These results support our previous results that $\mathrm{Cu}$ clusters grew in size by an instantaneous nucleation process during the initial stage. ${ }^{4}$ The higher the sweep rate, the lower the maximum of the scattered light intensity as shown in Fig. 5. Equation 3 shows that a smaller cluster and fewer clusters, i.e., a smoother surface, gives a less scattered light intensity. Thus, this scan rate dependence of the change of the intensity in the scattered light shows the differences in the condition of the GaAs surface. Figure 5 clearly shows that the electrode surface becomes smoother with a higher scan rate.

In the third region, the $\Delta R / R$ value increased with the charge corresponding to the electrodeposition of $\mathrm{Cu}$ and the scattered light intensity slightly increased, indicating that the surface roughness became nearly constant. These results suggest that in this region the diffusion layer of $\mathrm{Cu}^{2+}$ on the $\mathrm{Cu}$ clusters overlap each other with the growth of the $\mathrm{Cu}$ clusters. As a result of the overlap of the diffusion layers, the diffusion of the $\mathrm{Cu}^{2+}$ ion is available only in the $z$-direction and the growth mode of the $\mathrm{Cu}$ clusters changed from three dimensional to one dimensional ( $z$-direction). Thus, in this region, the thickness of the $\mathrm{Cu}$ layer increased with the deposition, but the roughness of the electrode surface only slightly changed. Moreover, the independence of the $(\Delta R / R) /$ charge ratio $v s$. the scan rate indicates that the thickness of the $\mathrm{Cu}$ layer increased at all scan rates in the same manner in this region.
Before the electrochemical dissolution of the deposited $\mathrm{Cu}$ started, the scattered light intensity increased, indicating an increase in the surface roughness. At the beginning of the electrochemical dissolution, i.e., at the potential where the anodic current started to flow, the scattered light intensity still increased, indicating that the electrochemical dissolution of the deposited $\mathrm{Cu}$ proceeded with the nucleation and growth process. Furthermore, the scattered light intensity returns to the original value at the top of the oxidation peak for $\mathrm{Cu}$ dissolution, showing that the dissolution process proceeds along with the nucleation process and produces a leveling process. Otherwise, the scattered light intensity must be constant during the dissolution process.

Deposition on the $\left(\mathrm{NH}_{4}\right)_{2} \mathrm{~S}$-treated GaAs surface.-Figure 6 shows the potential dependencies of the current, the $\Delta R / R$ value, and the scattered light intensity at the $\left(\mathrm{NH}_{4}\right)_{2} \mathrm{~S}$-treated $\mathrm{GaAs}(001)$ surface at the scan rate of $5 \mathrm{mV} \mathrm{s}^{-1}$. One should note that the scattered light intensity is not directly comparable to the results of the bare electrode because the relative position of the electrode and the detector were not exactly the same. The characteristics of the cyclic voltammograms and the potential dependence of the scattered light intensity obtained at the $\left(\mathrm{NH}_{4}\right)_{2} \mathrm{~S}$-treated surface were almost the same as those at the bare surface. Although the potential dependence of the $\Delta R / R$ value was apparently different from that at the bare surface, the essential feature was the same. The apparent difference was caused by the relatively small increase in the $\Delta R / R$ value during the deposition while the limiting current was flowing. This similarity can be more clearly seen in the charge dependencies of the $\Delta R / R$ value and scattered light intensity shown in Fig. 5e.

The $\Delta R / R$ value and the scattered light intensity linearly decreased and increased, respectively, with the charge in region II, and the $\Delta R / R$ value linearly increased while the scattered light intensity

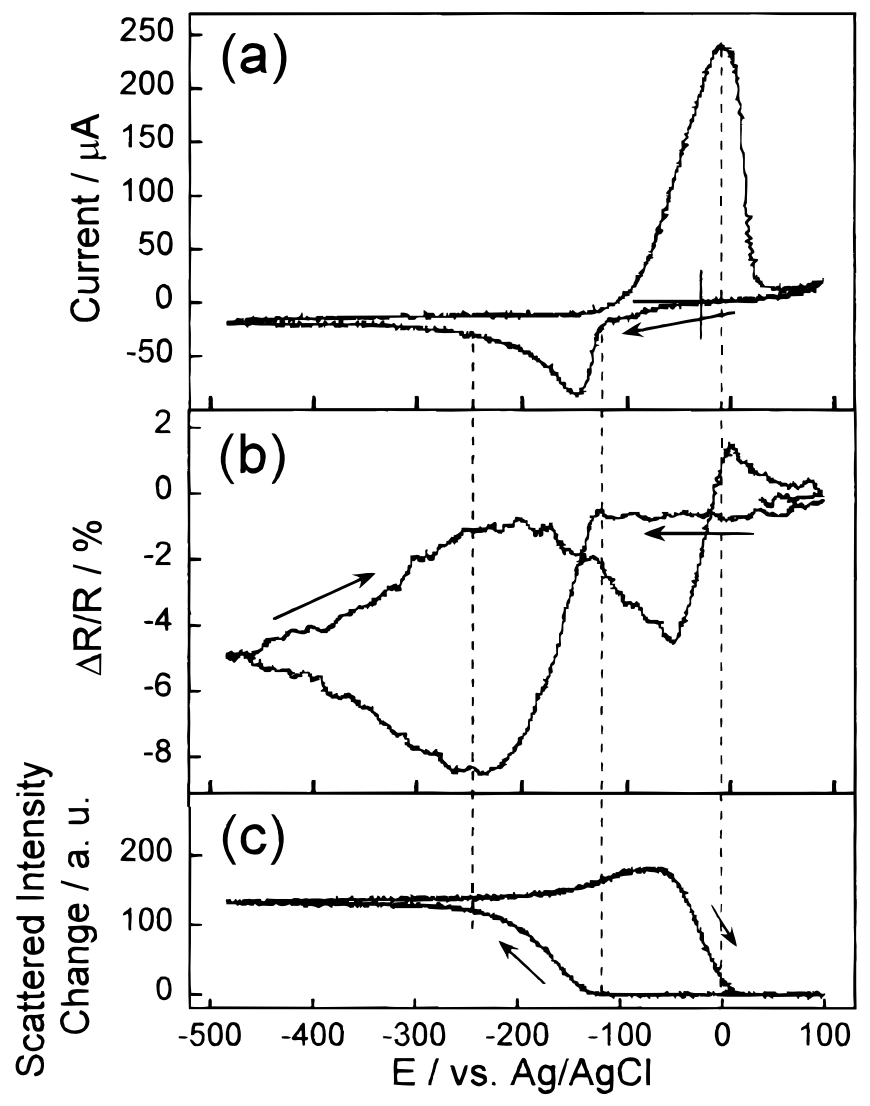

Figure 6. (a) Cyclic voltammogram, (b) $\Delta R / R$, and (c) scattered light intensity of $\left(\mathrm{NH}_{4}\right)_{2} \mathrm{~S}$-treated p-GaAs(001) electrode in $0.1 \mathrm{M} \mathrm{H}_{2} \mathrm{SO}_{4}$ solution containing $1 \mathrm{mM} \mathrm{CuSO}_{4}$. Sweep rate $5 \mathrm{mV} \mathrm{s}^{-1}$. 
(a)

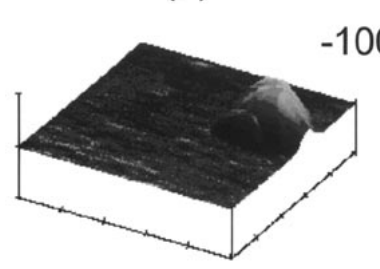

(b)
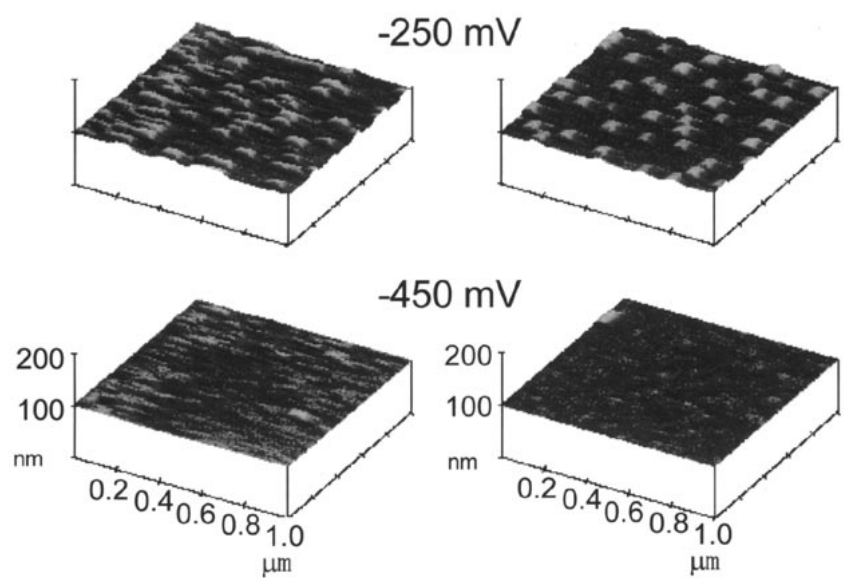

$-450 \mathrm{mV}$

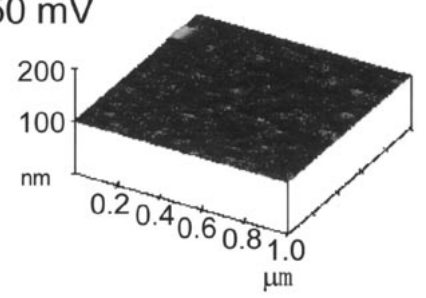

Figure 7. AFM images of (a) bare and (b) $\left(\mathrm{NH}_{4}\right)_{2} \mathrm{~S}$-treated p-GaAs(001) electrode in $0.1 \mathrm{M} \mathrm{H}_{2} \mathrm{SO}_{4}$ solution containing $1 \mathrm{mM} \mathrm{CuSO}{ }_{4}$ obtained $30 \mathrm{~s}$ after the potential of $-100 \mathrm{mV}$ (top), $-250 \mathrm{mV}$ (middle), and $-450 \mathrm{mV}$ (bottom) were applied.

increased rather slowly with the charge in region III, as was the case at the bare surface. The total charge passed during the deposition was, however, only half that on the bare surface, resulting in a relatively small increase of $\Delta R / R$. The smaller charge is due to the lower current. These results suggest that although the growth process of $\mathrm{Cu}$ clusters formed at the $\left(\mathrm{NH}_{4}\right)_{2} \mathrm{~S}$ surface was similar to that at the bare surface, the number of clusters formed on the $\left(\mathrm{NH}_{4}\right)_{2} \mathrm{~S}$-modified surface was less than those on the bare surface. Since the $\mathrm{Cu}$ deposition on $\mathrm{p}-\mathrm{GaAs}$, i.e., the cathodic process at a p-type semiconductor, in the dark can take place through surface states, the $\left(\mathrm{NH}_{4}\right)_{2} \mathrm{~S}$ treatment led to a decrease in the $\mathrm{Cu}$ deposition rate as a result of the reduction of the defect site that functions as the deposition site.

To confirm the reduction of the defect site by the $\left(\mathrm{NH}_{4}\right)_{2} \mathrm{~S}$ treatment, in situ electrochemical AFM measurements were carried out. Figure 7 shows the AFM images of the (a) bare and (b) $\left(\mathrm{NH}_{4}\right)_{2} \mathrm{~S}$ treated $\mathrm{GaAs}(001)$ after $30 \mathrm{~s}$ of $\mathrm{Cu}$ deposition at $-100,-250$, and $-450 \mathrm{mV}$. At $-100 \mathrm{mV}$, which is slightly more negative than the redox potential of $\mathrm{Cu}^{2+} / \mathrm{Cu}$, only some large $\mathrm{Cu}$ clusters were observed on both the surfaces. At $-250 \mathrm{mV}$, the number of $\mathrm{Cu}$ clusters is greater than that at $-100 \mathrm{mV}$ on both surfaces. It is clear that the number of clusters formed on the $\left(\mathrm{NH}_{4}\right)_{2} \mathrm{~S}$-treated surface is about half that on the bare surface. At $-450 \mathrm{mV}$, the $\left(\mathrm{NH}_{4}\right)_{2} \mathrm{~S}$-treated surface is smoother than the bare surface, supporting the abovementioned results obtained by the optical measurements.

Thus, the essential feature of the $\mathrm{Cu}$ deposition process on the $\left(\mathrm{NH}_{4}\right)_{2} \mathrm{~S}$-treated surface was almost the same as that on the bare electrode. The number of surface defects that work as absorption sites decreased to nearly half that of the bare surface by the $\left(\mathrm{NH}_{4}\right)_{2} \mathrm{~S}$ treatment, which is known to decrease the surface defects determined by the photoluminescence intensity measurement. ${ }^{19}$

\section{Conclusions}

$\mathrm{Cu}$ electrodeposition on bare and $\left(\mathrm{NH}_{4}\right)_{2} \mathrm{~S}$-treated p-GaAs $(001)$ surfaces was investigated by measurement of the potential dependence of the current, $\Delta R / R$, and scattered light intensity during the potential scan and in situ electrochemical AFM. Reflectance and light-scattering measurements showed that on both the bare and $\left(\mathrm{NH}_{4}\right)_{2} \mathrm{~S}$-treated surfaces, $\mathrm{Cu}$ deposition occurred in a cluster growth mode and the $\mathrm{Cu}$ clusters grew in the $z$-direction at a relatively negative potential where the limiting current was observed. The potential dependencies of the reflectance and scattered light intensity obtained at various scan rates showed that the size of the $\mathrm{Cu}$ cluster was smaller at the higher scan rate. The charge due to the $\mathrm{Cu}$ deposition at the $\left(\mathrm{NH}_{4}\right)_{2} \mathrm{~S}$-treated surface was nearly half that at the bare surface, and the AFM images showed a decrease in the number of $\mathrm{Cu}$ clusters, indicating that the $\left(\mathrm{NH}_{4}\right)_{2} \mathrm{~S}$ treatment reduced the defect sites on the surface. As a result, the $\left(\mathrm{NH}_{4}\right)_{2} \mathrm{~S}$ treatment provided more uniform $\mathrm{Cu} / \mathrm{GaAs}(001)$ interfaces in the large overpotential region.

\section{Acknowledgment}

We are grateful to H. Fujita and H. Fujisawa of the Mitsubishi Chemical Corporation for providing us with the GaAs single crystals. This work was partially supported by Grants-in-Aid for Scientific Research on Priority Area of "Electrochemistry of Ordered Interface" (no. 09237101) from the Ministry of Education, Science, Sports and Culture, Japan. article.

Hokkaido University assisted in meeting the publication costs of this References

1. P. M. Vereecken, F. V. Kerchove, and W. P. Gomes, Electrochim. Acta, 41, 95 (1996).

2. P. M. Vereecken, K. Strubbe, and W. P. Gomes, J. Electrochem. Soc., 145, 3075 (1998).

3. G. Scherb and D. M. Kolb, J. Electroanal. Chem., 396, 151 (1995).

4. M. Koinuma and K. Uosaki, Electrochim. Acta, 40, 1345 (1995).

5. M. Koinuma and K. Uosaki, Surf. Sci., 375-358, 565 (1996).

6. M. Koinuma and K. Uosaki, J. Electroanal. Chem., 409, 45 (1996).

7. D. M. Smilgies, R. Feidenhans'l, G. Scherb, D. M. Kolb, A. Kazimirov, and J. Zegenhagen, Surf. Sci., 367, 40 (1996).

8. K. Uosaki, T. Kondo, M. Koinuma, K. Tamura, and H. Oyanagi, Appl. Surf. Sci., 121-122, 102 (1997).

9. T. Kondo, K. Tamura, M. Koinuma, H. Oyanagi, and K. Uosaki, Chem. Lett., 761 (1997).

10. G. Scherb, A. Kazimirov, J. Zegenhagen, T. L. Lee, M. J. Bedzyk, H. Noguchi, and K. Uosaki, Phys. Rev. B, 58, 10800 (1998)

11. K. L. Kavanagh, R. S. Goldman, C. Lavoie, B. Leduc, T. Pinnington, T. Tiedje, D. Klug, and J. Tse, J. Cryst. Growth, 174, 550 (1997).

12. N. Wu, T. Hashizume, and H. Hasegawa, Jpn. J. Appl. Phys. Part 1, 33, 936 (1994).

13. K. Matsushita, N. Suzuki, S. Okuyama, and Y. Kumagai, Jpn. J. Appl. Phys. Part 1, 35, 5293 (1996).

14. V. N. Bessolov, E. V. Konenkova, and M. V. Lebedev, J. Vac. Sci. Technol. B, 14, 2761 (1996).

15. C. H. Chung, S. I. Yi, and W. H. Weinberg, Appl. Phys. Lett., 69, 3369 (1996).

16. S. Nozaki, S. Tamura, and K. Takahashi, J. Vac. Sci. Technol. B, 13, 297 (1995).

17. B. A. Kruvilla, A. Datta, G. S. Shekhawat, A. K. Sharma, P. D. Vyas, R. P. Gupta, and S. K. Kulkarni, Appl. Phys. Lett., 69, 415 (1996).

18. M. G. Kang, H. H. Park, K. S. Shu, and J. L. Lee, Thin Solid Films, 290-291, 328 (1996).

19. H. Sik, Y. Feurprier, C. Cardinaud, G. Turban, and A. Scavennec, J. Electrochem. Soc., 144, 2106 (1997).

20. C. J. Sandroff, M. S. Hegde, and C. C. Chang, J. Vac. Sci. Technol. B, 7, 841 (1989).

21. S. Maeyama, M. Suginama, and M. Oshima, Surf. Sci., 357-358, 527 (1996).

22. J. F. Fan, H. Oigawa, and Y. Nannichi, Jpn. J. Appl. Phys., 27, 761 (1988).

23. D. M. Kolb, in Spectroelectrochemistry, R. B. Gale, Editors, p. 87, Plenum Press, New York (1988).

24. L. Rayleigh, Proc. R. Soc. London, Ser. A, 84, 25 (1911).

25. D. E. Aspnes, G. P. Schwartz, G. J. Gualtieri, A. A. Studna, and B. Schwartz, J. Electrochem. Soc., 128, 590 (1981).

26. A. M. Kaminska and M. Guziewicz, Thin Solid Films, 254, 194 (1995). 